\title{
Erosion Caused by Coastal Structure
}

\author{
A.M. Salleh, N. Nadzir
}

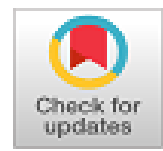

\begin{abstract}
Coastal structure such as jetties, groins, sea walls, breakwaters, etc. along the coast can alter the shoreline and morphological structure of coastline. Presence of the coastal structure gives impact like sediment trapping on upstream side of the structure and causing shore erosion along adjacent shorelines. Therefore, this paper presents attempts to describe the coastal erosion process effected by a different kind of coastal structure. Generally, it takes time to notes the impact of coastal erosion, therefore several methods are adapted to identify the erosion by surface sediment sampling and beach profile measurement. These measurements are conducted by conventional and high-technology method such as manual surface sediment sampling, Real-Time Kinematic (RTK) GPS, LiDAR and UAV. In terms of analysis, these methods can be approach with variable techniques and applications. However, this review paper briefly described the commonly used technique and application in finding the result of eroded coastal.
\end{abstract}

Keywords : Beach profile measurement, coastal erosion, coastal structure, surface sediment sampling.

\section{INTRODUCTION}

Coastal erosion happens when the shore loses sediment which resulting in a decrease of sediment budget [1]. However, coastline changes their shape and size from the time being as a response to the factor of waves, currents, and tides [2]. Other than the factor of natural processes, human activities such as construction on beach side, port side, shrimp farming, and offshore activities also contribute to coastal erosion [3].In addition to the beach construction, there is dire need for coastal protection since the residence of human beings in coastal regions exposed to flooding risk. As the standards of living and development have been increased in the coastal zones, coastal defense structures in terms of satisfactory performance have also been increased [4]. According to Meng-guo [5] and $\mathrm{Xu}$ [6] with the expenditure growth of the economy, as well as industrial and urban development, the contrarily of increasing people and decreasing land had become apparent. As solution, land reclamation is essential project to overcome this impact and expand the area of the city.

Hence, it has been considered since long to bring under

Revised Manuscript Received on October 30, 2019.

* Correspondence Author

Sr. Dr. Anuar Mohd Salleh*, Department of Infrastructure and Geomatic, Universiti Tun Hussein Onn Malaysia, Batu Pahat, Johor, Malaysia. Email: anuarms@uthm.edu.my

Nursyahillah Nadzir, Department of Infrastructure and Geomatic, Universiti Tun Hussein Onn Malaysia, Batu Pahat, Johor, Malaysia. Email: gf180063@siswa.uthm.edu.my

(C) The Authors. Published by Blue Eyes Intelligence Engineering and Sciences Publication (BEIESP). This is an open access article under the CC BY-NC-ND license (http://creativecommons.org/licenses/by-nc-nd/4.0/) control the land-based bottlenecks by construct marine reclamation and reduce erosion of coastal zone with coastal defense structure. Other than that, rising of ocean surface and turbulent sea will increase the number of coastal structure because protection is required for infrastructure, industrial activities and residential property [7]. However, construction of civil structures like sea walls, jetties, breakwaters, etc. along the coastline, either for evolution of ports and harbors or for conserve the coast from erosion [8]. Therefore, the purpose of this review is to describe the coastal erosion process effected by a different kind of coastal structure, methodologies are adopted to identify the erosion and recommend the most commonly used and excellent analysis.

\section{EFFECT BY COASTAL STRUCTURE}

The long-term coastal erosion encompasses regional areas mainly affected by the process of sea level variations and climatic changes [9]. Besides that, medium-term, involves factors that related to the sediment, mainly influenced by the river discharge, and shore protection [10]. However, erosion is related with the wave energy variations and linked to the process in short-term, e.g. storms [11]. The Nile Delta coast which is based in the centre part of the Egypt Mediterranean coast experienced changes in environmental conditions. For instance, there is erosion along the delta coast [12]. According to Iskandar [13], main coastal problem along this delta coast is the erosion due to dynamic influences while Nile River has reduce in sediment transport after High Aswan Dam development. Local also exposed erosion problems caused by protective measures. In addition to that, groins and seawalls were installed as beach invasion by urban constructions at Candeias Beach. These coastal structures were executed without thoroughly study the data of local coastal dynamics. This caused erosion downdrift, because of the dynamic equilibrium interruption of sediment transport in the area. In the year 2004, a 700 meters length of detached breakwater was installed 20 meters from the shore in a large wave energy area as shown in Fig. 1 (A) to protect coastline and adjacent area from erosion.

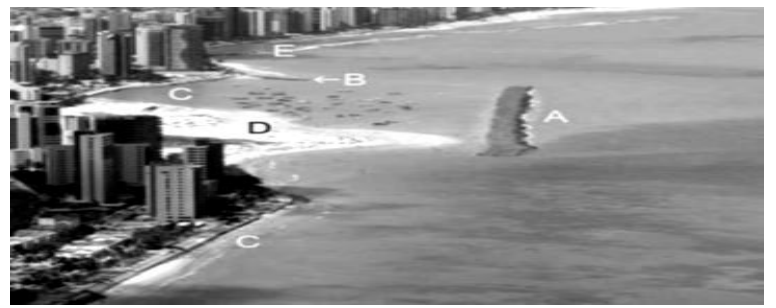

Fig. 1. Candeias Beach's coastal structures and its impact (A) detached breakwater (B) small groin, (C) reduction of sediment with seawall protections, (D) trapped sediment and (E) erosion at the north area [14]

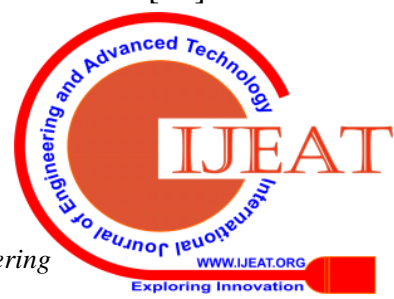


Erosion of beach is a serious concern for countries having coastal lines [15]. However, in order to protect from worst situation in the long-term period, the measurement of coastal erosion is required. Therefore, several methods can be applied to monitor the sedimentology and the changes of beach profile. These include surface sediment samples, airborne LIDAR (light detection and ranging) [16] and Unmanned Aerial Vehicles (UAVs) [17] as a remote sensing approach and satellite positioning approach which is Real-Time Kinematic (RTK) GPS.

\section{METHODOLOGIES}

The sediment measurement involves the sediment movements to indicate erosion or accretion in the area. It can be used to determined seasonal textural behavior along coastlines [18]. Meanwhile, beach profile measurement is very important to gain the information of erosion and sand deposition. Therefore, measurement of sediment and beach can be done in several methods either conventional or high technology such as manual sediment sampling, RTK GPS, LiDAR and UAV.

\section{A. Surface Sediment Sampling}

The work presented by Perbandaran Taman Negara [19], mud sampling consist of 17 sampling points with known coordinates was collected up to depth 2.0 meter at Tanjung Piai. Mud sampling was collected by using two types of sampling tools which are peat sampler and PVC tube sampler. The samples that have collected were preserved in zip-type plastic bags and labeled based on the location of sampling point and depth. The samples were put into containers and stored in the laboratory. In the study of coast of Teluk Wawasan, Ali et al. [20], have been identified 15 sampling points with known coordinate started from the lowest low tide to 1 kilometer to the mainland, along $2.6 \mathrm{~km}$ coast. The samples were taken on vertical strata so that the depth of $1 \mathrm{~m}$ at points S1 to S15 was undisturbed. The samples were taken using peat sampler and sent to the laboratory for analysis.

Furthermore, Haghshenas and Soltanpour [21] represented 28 sediment sampling executed at known points along the coast of Hendijan. Mud samples from $1 \mathrm{~m}$ top layer were taken through piston. In Simsek et al. [22] reported 71 samples were taken for study on the grain size of Datça and Hisarönü Bays in the southwest of Turkey. Samples were taken with sediment scoop representing the top $30 \mathrm{~cm}$ of the seafloor. About 25 sediment samplings were carried out along $1.2 \mathrm{~km}$ of Pantai Punggur and it is divided into two part. 15 Samples collection in 2012 and10 samples in 2013. The samples were collected at the sampling points using the peat sampler up to 1-m depth before taken to the laboratory for further analysis [23]. Figure 2 shows the sampling point along Pantai Punggur.

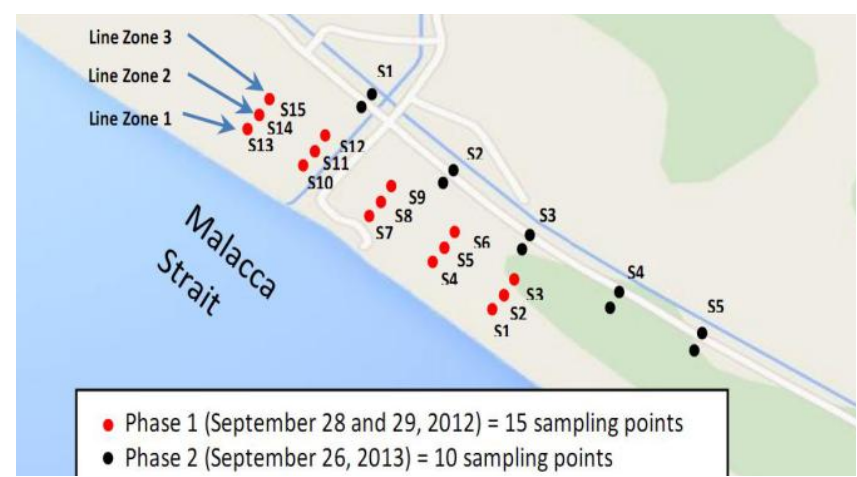

Fig. 2. Sketch map of 25 sampling points along $1.2 \mathrm{~km}$ at Pantai Puggur [23]

\section{B. Beach Profile Measurement}

- Airbone LiDAR (Light Detection and Ranging)

The uses of airbone LiDAR have been worked within South Korea in 2005 as a method to collect geographical data. However, earth surface data can be obtained from shoreline or mean surface height information [24].

In the year 2012 and 2013, Obu et al. [25] study the erosion of coastal and mass movement processes in the hinterland, Canadian Beaufort Sea by using $1 \mathrm{~m}$ horizontal resolution of airborne LiDAR elevation data. Results indicated that Shingle Point 2 site (Fig. 3), had constant coastal erosion until $10 \mathrm{~m}$ height from low coast and a varying high erosion order with greater backshore elevation along the coast. It also obtains the highest movement of coastline with temporal variability of $11.0 \pm 3.3 \mathrm{~m}$.

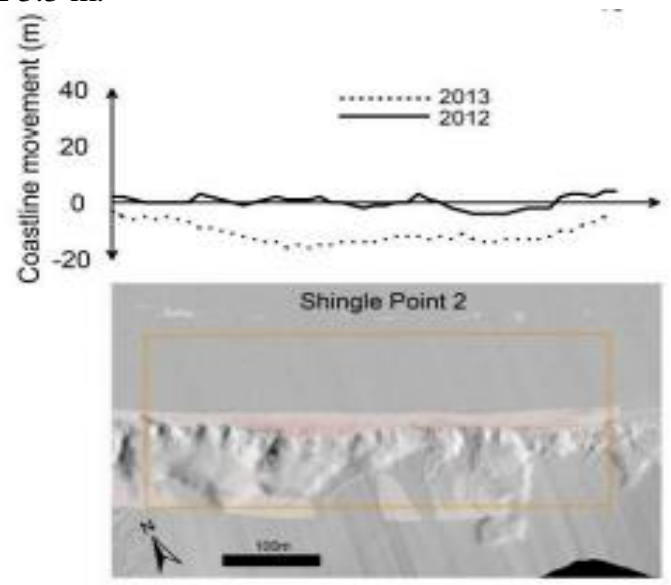

Fig. 3. The movement of coastline along the Canadian Beaufort Sea [25]

Hence, airborne LiDAR surveys cater fast and three-dimensional data with regard to big region. Meanwhile, conventional beach profile surveys cater data within limited area, often at the lower spatial resolution, and take several days to finish. Therefore, it is suggested that monitoring must be carried out at least twice a year [26].

\section{- Unmanned Aerial Vehicle (UAV)}

Observation on UAV is one of the photogrammetry methods used for mapping survey work. Although GPS surveying perhaps applied for coastal surveys [27], UAVs have been a well-set up equipment for high-resolution plan of small region [28]. 
The capability of UAVs photogrammetric has been examine currently in several studies. Most of the time, UAVs in general photogrammetric plan were applied to coastal surveying [29]. The accessibility of Digital Surface Models (DSM) at high resolution and accuracy is very functional for the landscape monitoring by 3D reconstruction of the terrain.

However, Kaamin et al. [30] reported the shoreline of Pantai Punggur changes more or less $1.42 \mathrm{~m}$ during high tide from August to November 2017. During the study within four months, result indicated that shoreline has changed and may give influenced to the coastal site. Inspection of shoreline changes and mapping was successfully achieved by using DJI Phantom 4 Pro UAV's set. Figure 4 shows the changes in shoreline within four months starting August 2017 until November 2017.

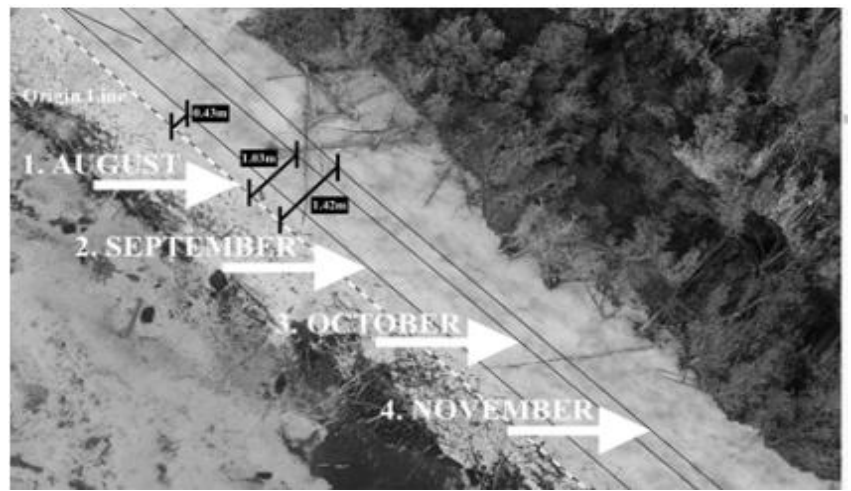

Fig. 4. The shoreline of four months during high tide define by lines [30]

\section{- Real-Time Kinematic (RTK) GPS}

This is a common approach based on method known as Differential Global Positioning System (DGPS). It comprise the collaboration of reference receiver stations, rovers, and satellite networks [31].

Kim et al. [32] studied that the total coastline changes for the period 2008 to 2011 were considered RTK GPS as shown in Figure 5. Variation of beach diameter $(\mathrm{m})$ and shore region (m2) were measured for every profile and mean for every coastal section to acquire the rates of coastline change $(\mathrm{m} / \mathrm{yr})$.

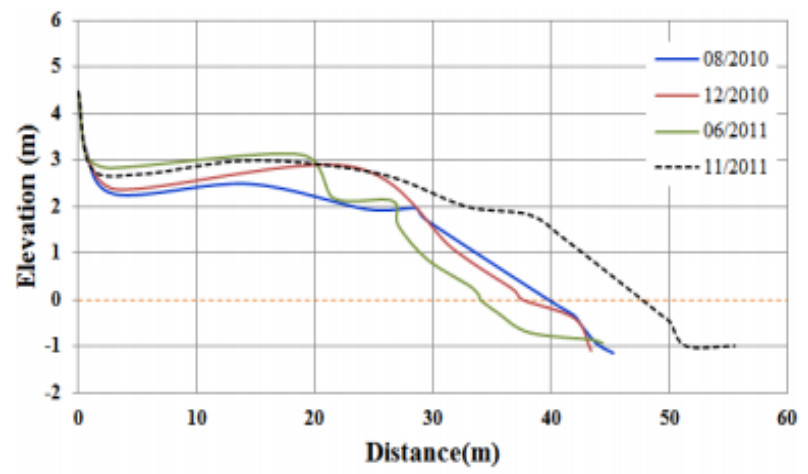

Fig. 5. The changes in shoreline from 2010 until 2011 at P5 zone [32]

\section{ANALYSIS}

To determine whether coastal was eroded, analysis need to be done. The collected sample and data can be analyze using variable method that depends on the output needed.

\section{A. Grain Size Distribution (GSD)}

Many studies have been considered particle size determination based on manual method and the automated instrumental method [33]. Particle size can be determined using various techniques, but this paper will be focused on sieving, sedimentation, and laser diffraction. These methods quantify dissimilar characteristic of the same material and classifications of particle size [34].

\section{- Sieving Method}

This method consists of sieves used to pass the sediment through it. The sediment retained on every layer of sieve was weighed and relative percentage was calculated with respect to total weight of sample. This method can be applied either dry or wet state. Lio et al. [35] air-dried the $250 \mathrm{~g}$ of soil sample, weighed and dry-sieved. The soil sample was put through 10 minutes automatic shaker for 3 times in a stack of ordered sieves. The soil distribution was evaluated by mass of every size after sieving process and sample were categorized as a sandy soil. Thus, the sieving method is the cheap and easy to use [36].

\section{- Sedimentation}

Particle fineness is generally evaluated through classical sedimentation methods like hydrometer or pipette [37]. Jamal et al. [38] reported, after comparing the particle size distribution as well as soil texture obtained by the standard pipette method against the hydrometer method, conclusion can be made that pipette method is considered an accurate method for particle size distribution. However, there are several advantages when using hydrometer method such as it is easy to complete a lot of samples analysis without great effort, no other chemicals are added, and no long waiting periods. However, sedimentation is the primeval techniques that were applied in particle size analysis. Its particle size limitations are in the range of less than $5 \mu \mathrm{m}$, and it is intensely sensible to particle geometry [39].

\section{- Laser Diffraction}

Laser diffraction particle size analyzer depicts the particle in multidimensional image while size dimension are from particle cross-sectional area. Moreover, following assumptions were considered for laser particle analyzer [40]: (i) diffraction patterns to particles sizes from analytical conversion is depends on matrices; (ii) particle orientation expected to be distribute at a random way [41].

Syvitski [42] considered laser diffraction and found that can handle particle sizes (less than $100 \mathrm{~nm}$ to $3 \mathrm{~mm}$ ). However, laser diffraction less good for coarse or nanomaterials. It is considered as intermediate solving method

\section{B. Digital Shoreline Analysis System (DSAS)}

The common indicator that shows the variations in coastal regions is Digital Shoreline Analysis System (DSAS) as a software continuation in the Environmental System Research Institute (ESRI) ArcGIS C [43] [44]. However, Nassar et al. [45] investigated on the Egypt shoreline changes from year 1989 to 2016 along North Sinai coast through geographic information system (GIS) and digital shoreline analysis system (DSAS). 
Changes shoreline including erosion and accretion patterns were taken into account by four (4) statistical parameters which are shoreline movement (NSM), endpoint rate (EPR), net linear regression rate (LRR), and least median of squares (LMS). El-Tinah plain bay's western seaside has immensely faced dynamical feature changes with mean erosion of -8.17 meters per year. Accretion happened at the east side of bay by the transportation of sediment from eastward alongshore current with an average of +4.28 meters per year. Figure 6 shows an example dataset (LRR, EPR, and WLR), and scaled to data (NSM).

\begin{tabular}{|c|c|c|c|c|}
\hline \multirow{2}{*}{\multicolumn{2}{|c|}{$\begin{array}{l}\text { RATES OF CHANGE (m/yr) } \\
\text { LRR, EPR, WLR }\end{array}$}} & \multicolumn{3}{|c|}{ DISTANCE MEASUREMENTS (m) } \\
\hline & & & NSM & SCE \\
\hline MIN $<-<=-3.07$ & & MIN & $<-<=-473$ & (positive values only) \\
\hline$-3.0<-<=-2.0$ & NEGATIVE & .473 & $3<-<=-315$ & \\
\hline$-2.0<-<=-1.0$ & & -315 & $j<-<=-157$ & \\
\hline$-1.0<<<=-0.5$ & & -157 & $<<<=-10$ & \\
\hline$-0.5<\longrightarrow<=0.5$ & & -10 & $<<<=10$ & $0.0<<<=126$ \\
\hline $0.5<-<=1.0$ & & 10 & $<<<=175$ & $126<<<=253$ \\
\hline$<-<=2.0$ & POSITIVE & 175 & $<-<=350$ & $253<-<=379$ \\
\hline$<-<=3.0$ & POSIIVE & 350 & $<-<=525$ & $379<-<=506$ \\
\hline$<-<=$ MAX $]$ & & 525 & $\begin{array}{c}<-<=\text { MAX } \\
\cdots \text { NULL }\end{array}$ & $\begin{array}{c}506<-<=\text { MAX } \\
\text { NULL }\end{array}$ \\
\hline
\end{tabular}

Fig. 6. Example of fixed bin options (left) for rates of change dataset (LRR, EPR, and WLR), and scaled to data (right)

(NSM) [45]

\section{Agisoft Photoscan software}

In recent years, the orthophoto products through photogrammetry courses have been conventional measurement for almost any survey mapping method in developed countries. It has made a mapping in any survey method such as engineering surveying, geographic information system (GIS), and possibly in the cadastral survey in the future. It was suggested by Muneza et al. [46] whereby the orthophoto product was used to digitize detailed spatial datasets such as base maps and cadastral, then guide development for economic planning in countries. A good result of orthophoto mapping encouraged by a combination of mapping performance and image representation [47]. Through UAV platform generated orthophoto, it is important to know the accuracy of software used to minimize the error in processing UAV aerial photograph.

The research by Abdur Rani and Rusli [48] in the accuracy of orthophoto comparison is made by two different software, Agisoft PhotoScan, and Pix4D. Based on the findings, Agisoft PhotoScan is more outstanding in both quantitative and qualitative analysis, but low in brightness of orthophoto visual compared to Pix4D Mapper. However, both software are suitable to process UAV images as the accuracy is still under acceptance based on the ASPRS guidelines. Figure 7 shows the difference between two orthophotos generated.

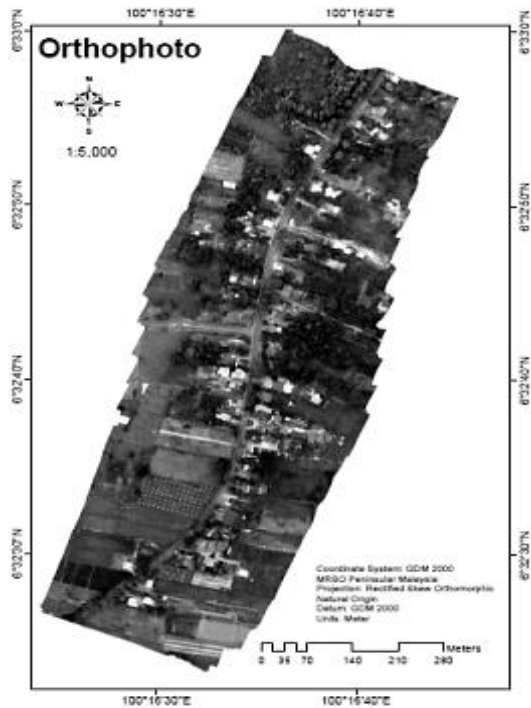

(a)

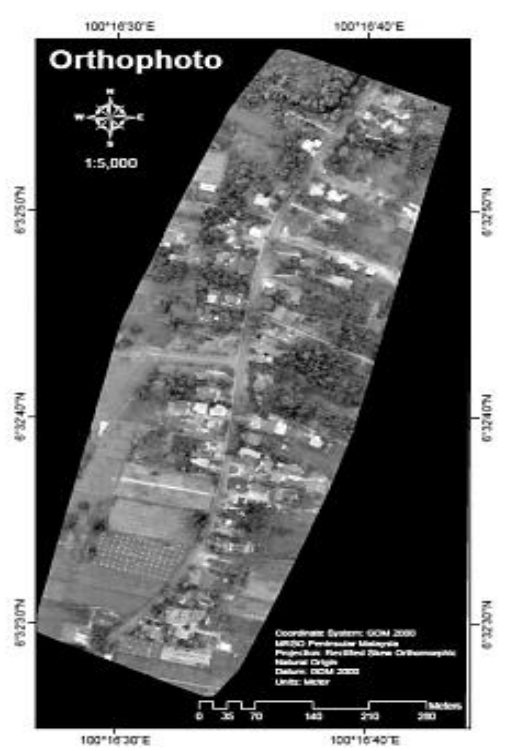

(b)

Fig. 7. The orthophoto that generated (a) Agisoft PhotoScan and (b) Pix4D Mapper [48]

\section{CONCLUSION}

Referring to all studies that have been conducted, clearly indicates that the coastal structure does indeed contributed to the erosion of coastal water. The erosion level also determine by the type and size of the structure, as well as the geographical factors of the affected area. The method for determining this erosion can be divided into direct approach methods such as manual sampling and high technology-oriented methods such as RTK GPS, LiDAR, and UAV are widely used as they can cover a wider area with no weather constraints and easier access.

In terms of analysis, various techniques can be used depending on the desired output type. Grain size distribution (GSD) analysis was using sieving, sedimentation, and laser diffraction method and each method have their advantages and limitations. 
Process of measurement, quantify, calculate and monitor shoreline rate-of-change statistics, most basic approached and has been used by many researchers are using DSAS software extension within ArcGIS. Besides that, analysis of creating orthophoto map using Agisoft Photoscan software good in quantitative and qualitative analysis rather than Pix4D Mapper. Thus, the cause of coastal erosion, methods, and most excellent analysis to identify the erosion are briefly discussed.

\section{ACKNOWLEDGMENT}

This review paper is fully financed by Universiti Tun Hussein Onn Malaysia GPPS Grant Scheme (Vot H292: Establishment of Data Observation Station at Tanjung Laboh and Its Impact on Physical Oceanography) and TIER 1 Grant Scheme (Vot U846: Development of Ocean Surface Wave Monitoring System). The authors thanks to Universiti Tun Hussein Onn Malaysia for the approved fund which makes this paper viable and excellent.

\section{REFERENCES}

1. D.R. Basco, "Overview of Beach Engineering in the United States of America. Final Report, Coastal Engineering Centre," Old Dominion University, Virginia, 1999, pp 116.

2. T. Garrison, "Oceanography: An Invitation to Marine Science." 5thed (Belmont, California: Brooks/Cole-Thomson Learning, 2005).

3. P. Burka, "Shoreline Erosion: Implication for Public Right and Private Ownership." Coastal Zone Management Journal. 1(2), 1974, pp. 175-191.

4. A. Jahangirzadeh, S. Akib, B. Kamali, N.S. Shamsudin, and K. Kimiaei, "Effects of Construction of Coastal Structure on Ecosystem," World Academy of Science, Engineering and Technology, 65, 2012, pp. 663-674.

5. L. Meng-Guo, "The Effect of Reclamation in Areas between Islands in a Complex Tidal Estuary on the Hydrodynamic Sediment Environment," Journal of Hydrodynamics, 22(3), 2010, pp. 338-350.

6. T. Xu, "Study of Morphological Changes Induced by Man-Made Coastal Project," Advanced Materials Research, 2014, pp. 989-994, pp. 1240-1243.

7. L.B. Firth, R. Thompson, K. Bohn, M. Abbiati, L. Airoldi, T. Bouma, ... S. Hawkins, "Between a rock and a hard place: Environmental and engineering considerations when designing coastal defence structures," Coastal Engineering, 87, 2014, pp. 122-135.

8. P.K. Mohanty, S.K. Patra, S. Bramha, B. Seth, U. Pradhan, B. Behera, ... U. S. Panda, "Impact of Groins on Beach Morphology: A Case Study near Gopalpur Port,” East Coast of India, Journal of Coastal Research, 279, 2012, pp. 132-142.

9. N.G. Rangel-Buitrago, G. Anfuso, and A.T. Williams, "Coastal erosion along the Caribbean coast of Colombia: Magnitudes, causes, and management," Ocean \& Coastal Management, 114, 2015, pp. 129-144.

10. J.A. Cooper, and O.H. Pilkey, "Alternative" Shoreline Erosion Control Devices: A Review," Pitfalls of Shoreline Stabilization Coastal Research Library, 2012, pp. 187-214.

11. N. Rangel-Buitrago, G. Anfuso, "Winter wave climate, storms, and regional cycles: the SW Spanish Atlantic coast," Int. J. Climatol, 33, 2013, pp. 2142-2156.

12. M.M. El Banna, O.E. Frihy, "Human-induced changes in the geomorphology of the northeastern coast of the Nile Delta, Egypt," Geomorphology 107, 2009, pp. 72-78.

13. M. Iskander, "Environmental friendly methods for the Egyptian coastal protection, in: Coastal Zone Management of River Deltas and Low Land Coastlines," CZMRDLLC. 2010. pp. 625-642.

14. E. Brandon, and L.N. Steven, "Changes in shoreline change trends in response to a detached breakwater field at Grand Isle, Louisiana," Journal of Coastal Research, 27(4), 2011, pp. 698-705.

15. J. Cheng, P. Wang, and Q. Guo, "Measuring Beach Profiles along a Low-Wave Energy Microtidal Coast," West-Central Florida, USA, Geosciences, 6(4), 2016, pp. 44.

16. S. Saye, D. van der Wal, and K. Pye, "Beach-dune morphological relationships and erosion/accretion: An investigation at five sites in
England and Wales using lidar data," Geomorphology. 72, 2005, pp. 128-155.

17. I.L. Turner, M.D. Harley, C.D. Drummond, "UAVs for coastal surveying." Coast. Eng, 114, 2016, pp. 19-24.

18. G. U Dora, S. K. Kumar, C. S. Philip, P. Vinayaraj, and R. Gowthaman, "Textural Characteristics of Foreshore Sediments Along Karnataka Shoreline," West Coast of India, Int. J. Sedim. Res, 26, 2011, pp. 364-377.

19. Perbandaran Taman Negara, (Consultancy Project: Physical and Biological Condition After the Wavebreaker Bunds At Tanjung Piai Johor National Park), 2017.

20. M.Z. Ali, W.L. Tan, L.M. Khalid, "Morfologi dan Taburan Sedimen di Teluk Wawasan.” Persidangan Kebangsaan Geografi \& Alam Sekitar Kali Ke 4. Anjuran Jabatan Geografi dan Alam Sekitar, Fakulti Sains Kemanusiaan, Universiti Pendidikan Sultan Idris, 2013, pp. 459-466 (in Malay).

21. S. A. Haghshenas, and M. Soltanpour, "An analysis of wave dissipation at the Hendijan mud coast, the Persian Gulf," Ocean Dynamics, 61(2-3), 2010, pp. 217-232.

22. B. Şimşek, M. Ergin, M. Evren, Ö. Türkmen, S. Palas, H. Pehlivan, .. F. Öcal, "Grain Size, Total Heavy Mineral And Element Distribution And Control Factors Of Current Sediments On The Floor Of Hisaronu And Datca Bays," Bulletin of the Mineral Research and Exploration, 154, 2017, pp. 45-45.

23. M.Z. Ali, W.L. Tan, S.S.M.M. Tahar, A.A.F. Hakimd, "Sediment properties of Pantai Punggur," Proceedings of Sixteenth The IIER International Conference, Kuala Lumpur, Malaysia, 2015, pp. 114-119.

24. R. Gutierrez, J. Gibeaut, R. Smyth, T. Hepner, J. Andrews, C. Weed, W. Gutelius, M. Mastin, "Precise Airborne lidar surveying for Coastal Research and Geo-Hazards Applications, International Archives of Photogrammetry and Remote Sensing," Volume XXXIV-3/W4, 2002, pp. 185-192.

25. J. Obu, H. Lantuit, G. Grosse, F. Günther, T. Sachs, V. Helm, and M. Fritz, "Coastal erosion and mass wasting along the Canadian Beaufort Sea based on annual airborne LiDAR elevation data," Geomorphology, 293, 2017, pp. 331-346.

26. K. Pye, S.J. Blott, "Assessment of beach and dune erosion and accretion using LiDAR: impact of the stormy 2013-14 winter and longer term trends on the Sefton Coast," UK Geomorphology, 266, 2016, pp. 146-167.

27. S. Madeira, J.A. Gonçalves, L. Bastos, Accurate DTM generation in sand beaches using mobile mapping, J. Coast. Conserv, 17, 2013, pp. 79-588.

28. F. Remondino, L. Barazzetti, F. Nex, M. Scaioni, D. Sarazzi, "UAV photogrammetry for mapping and 3D modeling - current status and future perspectives," Int. Arch. Photogramm. Remote Sens. 63, 2011, pp. 25-31.

29. P. Barry, R. Coakley, "Accuracy of UAV photogrammetry compared with network RTK GPS," Int. Arch. Photogramm. Remote Sens, XL-1/W2, 2013, pp. 27-31.

30. M. Kaamin, M. E. Daud, M. E. Sanik, N. F. Ahmad, M. Mokhtar, N. Ngadiman, and F. R. Yahya, "Mapping shoreline position using unmanned aerial vehicle," AIP Conference Proceedings, 2018.

31. J.M Lee, J.Y Park, J.Y. Choi, "Evaluation of Sub-aerial Topographic Surveying Techniques Using Total Station and RTK-GPS for applications in Macro-tidal Sand Beach Environment," Proceedings 12th International Coastal Symposium Plymouth, England, 65, 2013, pp. 535-540.

32. I.H. Kim, H.S. Lee, W.C. Cho, and D.S. Song, "Shoreline changes due to groin construction in Namae and Sodol Beaches, South Korea," Proceedings 12th International Coastal Symposium Plymouth, England, 2013, pp. 2131-2136.

33. H. Chen, H. Tang, Y. Liu, H.Wang, G. and Liu, "Measurement of particle size based on digital imaging technique," Journal of Hydrodynamics, 25(2), 2013, pp. 242-248.

34. S. Kimura, T. Ito, and H. Minagawa, "Grain-size analysis of fine and coarse non-plastic grains: Comparison of different analysis methods," Granular Matter, 20(3). 2018.

35. X. Liao, Y. Li, and X. Yan, "Removal of heavy metals and arsenic from a co-contaminated soil by sieving combined with washing process," Journal of Environmental Sciences, 41, 2016, pp. 202-210.

36. R. L. Folk, Petrology of Sedimentary Rocks (Austin: Hemphill Publishing, 1980). 
37. G. W. Gee, J. W. and Bauder, Particle-size analysis. In J. H. Klute (Ed.), Methods of soil analysis, Part 1 (2nd ed.).Agron. Monogr, 9, 1986, pp. 383-411.

38. J.T. elfaki, M.A. Gafer, M.M. Suleiman, M. E. Ali, "Hydrometer method against Pippete method for estimating soil particles size distribution in some soil types selectedfrom central sudan," International Journal of Engineering research and advance technology (IJERAT), 2(2), 2016, pp. 25-41.

39. N. Stanley-Wood, and R.W. Lines, Particle Size Analysis (Cambridge: Royal Society of Chemistry. Royal Society of Chemistry, Special Publication 102, 1992).

40. M. Konert, and J. Vandenberghe, "Comparison of laser grain size analysis with pipette and sieve analysis: a solution for the underestimation of the clay fraction," Sedimentology, 44, 1997, pp. 523-525

41. C. Di Stefano, V. Ferro, and S. Mirabile, "Comparison between grain size analyses using laser diffraction and sedimentation methods," Biosys. Eng., 106, 2010, pp. 205-215.

42. J.P.M. Syvitski, "Principles, Methods and Application of Particle Size Analysis," Cambridge: Cambridge University Press, 2007.

43. T.D.T. Oyedotun, Shoreline Geometry: DSAS as a Tool for Historical Trend Analysis, British Society for Geomorphology (Geomorphological Techniques, 2014) Chap. 3, Sec. 2.2.

44. E. R. Thieler, Digital Shoreline Analysis System (DSAS) Version 3.0: An Arcgis extension for calculating shoreline change. Open File Report 2005-1304, United States Geological Survey, 2015.

45. K. Nassar, H. Fath, W. E. Mahmod, A. Masria, K. Nadaoka, and A. Negm, "Automatic detection of shoreline change: Case of North Sinai coast, Egypt," Journal of coastal conservation, 22(6), 2018, pp. 1057-1083.

46. J. M. Muneza, N. K. Mila, G. Markus, N. Francesco, G. Caroline, "A Photogrammetry Approach for Map Updating using UAV in Rwanda, GeoTech Rwanda," 2015, pp 1-8.

47. C. Toth, and D.G. Brzezinska, "Rapid Orthophoto Development System. The Ohio State University," 2013, pp. 1-104.

48. M.F. Abdur Rani, and N. Rusli, "The Accuracy Assessment of Agisoft PhotoScan and Pix4D Mapper Software in Orthophoto Production," Geomatics Research Innovation Competition, 1, 2017, pp. 1-4.

\section{AUTHORS PROFILE}

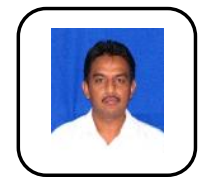

Sr. Dr. Anuar Mohd Salleh received BSc. of Geomatic Engineering from Universiti Teknologi Malaysia (UTM) He gained his Masters of Land Survey at UTM and PhD in Civil Engineering in Universiti Tun Hussein Onn Malaysia (UTHM). Sr. Dr. Anuar is currently a senior lecturer from Department of Infrastructure and Geomatics, Faculty of Civil and Environmental Engineering in UTHM. His research interests are in the area of ocean wave, environment monitoring and changes, Global Positioning System (GPS) and geomatics. He is also a member of Royal Institution of Surveyor Malaysia (RISM) in 2017 until present.

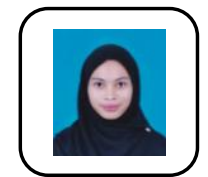

Nursyahillah Nadzir holds a BEng (Hons) degree in Civil and Environmental Engineering from Universiti Tun Hussein Onn Malaysia (UTHM) in 2018 and currently, she is a MEng candidate in Department of Infrastructure and Geomatics, Faculty of Civil and Environmental Engineering, UTHM. She is also a member of Board of Engineers Malaysia (BEM) in 2018. Her current research interest is in the area of Coastal and Ocean Engineering. 